\title{
FTIR study of hydrotalcite
}

\author{
Miroslava Mališováa ${ }^{a}$ Michal Horňáček ${ }^{a}$, Jozef Mikulec ${ }^{b}$, \\ Pavol Hudec ${ }^{a}$, Vladimír Jorík \\ ${ }^{a}$ Department of Organic Technology, Catalysis and Petroleum Chemistry, \\ Faculty of Chemical and Food Technology Slovak University of Technology, \\ Radlinského 9, 81237 Bratislava, Slovak Republic \\ ${ }^{b}$ Research Institute of Petroleum and Hydrocarbon Gases, \\ Vlčie Hrdlo, 82003 Bratislava, Slovak Republic \\ ${ }^{c}$ Department of Inorganic Chemistry, Faculty of Chemical and Food Technology Slovak University of Technology, \\ Radlinského 9, 81237 Bratislava, Slovak Republic \\ mamiroslava@gmail.com
}

\begin{abstract}
The aim of the research was the study of aluminium-magnesium hydrotalcite by FTIR analysis and detection of differences in structure due to calcination. Three types of samples were analysed. In the first two samples, cobalt was added into the structure and the third sample contained nickel and zinc. Hydrotalcite was prepared by one of the most common methods of hydrotalcite preparation, co-precipitation. After preparation, the samples were calcined at temperatures from $150{ }^{\circ} \mathrm{C}$ to $750{ }^{\circ} \mathrm{C}$. Samples were compared in terms of calcination temperature; but in case of samples containing cobalt, two samples to each other. The most significant changes were noticed in the $500-700 \mathrm{~cm}^{-1}$ region, where a spinel structure was formed at higher calcination temperatures.
\end{abstract}

Keywords: hydrotalcite, FTIR, co-precipitation, catalyst, calcination

\section{Introduction}

Hydrotalcite (HT) belongs to the group of double layer hydroxides (LDH) and its structure is described by the chemical formula:

$$
\left[\mathrm{M}_{\mathrm{n}}{ }^{2+} \mathrm{M}_{\mathrm{m}}{ }^{3+}(\mathrm{OH})_{2(\mathrm{n}+\mathrm{m})}\right]_{\mathrm{m}}{ }^{+}\left[\mathrm{A}_{\mathrm{x}}{ }^{-}\right]_{\mathrm{m} / \mathrm{x}} \cdot{ }_{\mathrm{y}} \mathrm{H}_{2} \mathrm{O},
$$

where $\mathrm{M}^{2+}$ and $\mathrm{M}^{3+}$ are divalent and trivalent metal cations and $A_{x}$ is an m-bonding anion. The layered HT structure is based on the rotation of positively charged $\left(\mathrm{M}^{2+}\right.$ and $\left.\mathrm{M}^{3+}\right)(\mathrm{OH})_{6}$ octahedral layers similarly to the structure of brucit $\left(\mathrm{Mg}(\mathrm{OH})_{2}\right)$ and negatively charged interlayers consisting of anions and water molecules. Anions are divalent e.g. carbonate, sulphate or nitrate (Kikhtyanin at al., 2016; Yang et al., 2016; Muriithi et al., 2016).

The range of metal cations which may be incorporated into the positive charge layer is relatively wide and is determined by their size, which should be similar to that of $\mathrm{Mg}^{2+}$ for divalent cations and that of $\mathrm{Al}^{3+}$ for trivalent cations (Basag et al., 2016).

The most commonly used divalent metal cations that can be used in HT are: $\mathrm{Mg}^{2+}, \mathrm{Fe}^{2+}, \mathrm{Ni}^{2+}$, $\mathrm{Cu}^{2+}, \mathrm{Co}^{2+}, \mathrm{Mn}^{2+}, \mathrm{Zn}^{2+}$ or $\mathrm{Cd}^{2+}$ and trivalent metal

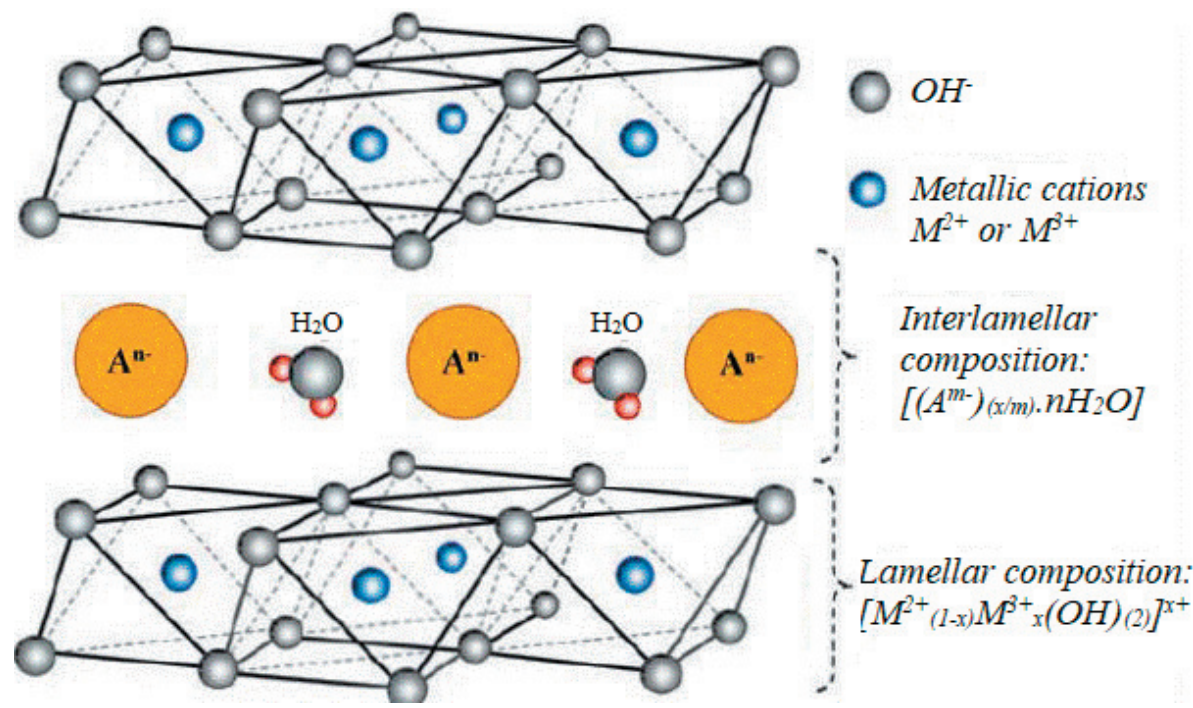

Fig. 1. General structure of hydrotalcite (Salomão et al., 2013). 
cations such as $\mathrm{Al}^{3+}, \mathrm{Cr}^{3+}, \mathrm{Ga}^{3+}$ or $\mathrm{Fe}^{3+}$. Metal cationcontaining sheets have a similar structure as brucid, where cations randomly occupy octahedral holes in narrow configuration with $\mathrm{OH}^{-}$ions.

Anions and water are dispersed in the interlayer where they can move by breaking the bonds and forming new ones (like in liquid water) (Cavani at al., 1991). Intermediate water stabilises the crystalline structure. Weak chemical bonds between the sheet structure and the interlayer anions contribute to the ion exchange abilities of HT. Due to its properties and the content of ions in the interlayer, HT is included in the group of anionic clays (Yang et al., 2016).

\section{Hydrotalcite memory effect}

One of the outstanding properties of hydrotalcite is the memory effect which is reflected in the calcination of HT materials in the removal of interlayer anions and hydroxyl groups of water.

Calcined HT is able to re-acquire the original layered structure when exposed to the anion in an aqueous solution, which is controlled by two factors. First one is the choice of reference material, which has to contain thermally labile anions. Second one and an important condition is the calcination temperature, which has to be controlled to avoid overheating. In case of excessive heating, a spinel structure resistant to rehydration is formed. The memory effect helps create a ready-to-use material that can be used in a variety of applications. Uniform distribution of these mixed oxides and homogeneous mixtures makes the studied material a potential catalyst for a variety of organic transformations (Baskaran et al., 2015).

\section{Synthesis}

Different methods are used to synthesise HT depending on specific requirements and properties. Widely recognised methods include co-precipitation, urea hydrolysis and hydrothermal microwave radiation (Baskaran et al., 2015). One of the possible ways of hydrotalcite preparation is the use of hydrotalcite memory effect or the classical process of ion exchange. In addition to these methods, there are, for example, sol-gel processes using ethanol and acetone (He et al., 2005). Co-precipitation is the most used method of HT production. It is the precipitation of dissolved components of the solution with macro components from the same solution to form mixed crystals by adsorption, occlusion or mechanical interception. Precipitation can take two different ways: precipitation with variable $\mathrm{pH}$, where the salt solution containing the divalent and trivalent cations is successively added to the alkaline solution containing the anions; or precipitation with constant $\mathrm{pH}$ throughout the reaction. At such $\mathrm{pH}$, the solution of the two- and trivalent cations is mixed together with the interlayer anions and the alkaline solution. However, this second method requires a more sophisticated device. With an increasing $\mathrm{pH}$, $\mathrm{Mg}^{2+}$ and $\mathrm{Al}^{3+}$ (or other used divalent and trivalent ions) react with $\mathrm{OH}^{-}$and $\left(\mathrm{CO}_{3}\right)^{2-}$ anions and hydrotalcite is formed precipitates due to its very low solubility. The whole reaction is carried out under strong stirring, which requires a further purification step to remove all counter ions remaining in the solution. Reaction conditions have to be strictly controlled during the whole reaction; in particular: concentration of the reactants, final $\mathrm{pH}$, degree of agitation and, last but not least, the temperature of the mixture. Precipitation typically takes place at a relatively low temperature (maximum up to $35^{\circ} \mathrm{C}$ ) to prevent the formation of other products such as simple hydroxides (Salomão et al., 2013).

\section{Experimental}

For samples preparation, co-precipitation of metal nitrates in $\mathrm{Na}_{2} \mathrm{CO}_{3}$ at constant $\mathrm{pH}$ was applied. Three solutions were prepared. The first was the metal nitrate solution (solution A), which contained the selected metal ions. For Co/HT-1 and Co/ HT-4 samples it was magnesium, aluminium and cobalt. In the $\mathrm{ZnNi}$ HT-6 sample, it was magnesium, zinc, aluminium and nickel. Solution A was prepared as a salt solution containing divalent and trivalent cations to be provided to the cationic layer. Solution B contained a 0.05 mole $\mathrm{Na}_{2} \mathrm{CO}_{3}$ solution and solution $\mathrm{C}$ contained $0.1 \% \mathrm{NaOH}$. Solution A was gradually added to solution $\mathrm{B}$ at the rate of $4 \mathrm{~mL} / \mathrm{min}$ and under stirring at $25^{\circ} \mathrm{C}$. Solution $\mathrm{C}$ served to adjust the precipitation $\mathrm{pH}$, which was maintained at $7.9 \leq \mathrm{pH} \geq 8.1$. The $\mathrm{pH}$ value was controlled using a pH meter (enomenal 1000L) with the accuracy of \pm 0.1 . The precipitated hydrotalcite was subsequently purified and calcined at $150{ }^{\circ} \mathrm{C}, 250{ }^{\circ} \mathrm{C}, 350{ }^{\circ} \mathrm{C}, 450{ }^{\circ} \mathrm{C}, 550{ }^{\circ} \mathrm{C}, 650{ }^{\circ} \mathrm{C}$ and $750{ }^{\circ} \mathrm{C}$. The prepared samples were placed in an airtight desiccator until the preparation of the FTIR analysis tablets with KBr. A comparative tablet containing $300 \mathrm{mg}$ of $\mathrm{KBr}$ was prepared as first. Potassium bromide, used for the tablets preparation was dried ( 8 hours at $140{ }^{\circ} \mathrm{C}$ ) and ground to powder. For the preparation of one tablet, $0.3 \mathrm{mg}$ of the sample and $300 \mathrm{mg}$ of $\mathrm{KBr}$ were weighed. Weighed amount of $\mathrm{KBr}$ was mixed with the weighed sample and placed in a vibratory mill, where the mixture was homogenized and milled (60-80 seconds). Homogenized sample was poured into the mould to achieve an approximately same layer by turning the mould piston under gentle pressure. The mould- 
ing form was pressed in the press so that the flexible seal was sealed and the mould was evacuated with an oil rotary tube for about 2 minutes. The sample was pressed under the pressure of about $10 \mathrm{MPa}$ for 5 minutes under constant evacuation. Moisture in the sample may be due to the addition of $\mathrm{KBr}$ in the tablets preparation.

\section{Result and Discussion}

Tab. 1. Composition of hydrotalcites.

\begin{tabular}{lc}
\hline Sample & Composition \\
\hline $\mathrm{Co} / \mathrm{HT}-1$ & $\mathrm{Al}_{1} \mathrm{Mg}_{0.4} \mathrm{Co}_{4.6} \mathrm{O}_{3.8}$ \\
$\mathrm{Co} / \mathrm{HT}-4$ & $\mathrm{Al}_{1} \mathrm{Mg}_{0.5} \mathrm{Co}_{2.5} \mathrm{O}_{2.6}$ \\
$\mathrm{ZnNi} / \mathrm{HT}-6$ & $\mathrm{Al}_{1} \mathrm{Mg}_{0.9} \mathrm{Zn}_{1.0} \mathrm{Ni}_{1.1} \mathrm{O}_{2.9}$ \\
\hline
\end{tabular}

Table 1 shows the composition of hydrotalcites of the prepared samples. In this work, we analysed three samples with different metal contents. The first two samples contained cobalt as an added metal. In Table 1, differences in the elementary analyses in two samples can be seen. In the third sample, nickel and zinc were the added metals.

\section{Co/HT-1}

The first sample, which was measured by the FTIR analysis, was Co/HT-1, which contained cobalt in its structure. As it can be seen in Table 2, the first intense peaks in the wavelength range of $3500 \mathrm{~cm}^{-1}$ and $3470 \mathrm{~cm}^{-1}$ correspond to the stretching vibrations of hydroxyl groups of water in the interlayer space. In the non-calcined sample, the peak intensity is high and with increasing the calcination temperature, the peak intensity decreases. This is due to water loss caused by calcination. The most significant decrease was observed in the sample calcined at $550{ }^{\circ} \mathrm{C}$. For samples calcined at $250{ }^{\circ} \mathrm{C}, 350{ }^{\circ} \mathrm{C}, 650^{\circ} \mathrm{C}, 750{ }^{\circ} \mathrm{C}$, non-intense peaks were shown at the wavelength of $2364-2923 \mathrm{~cm}^{-1}$.

Also, Débor M. Bezerr et al. explain the formation of these peaks caused by the bond between
$\mathrm{CO}_{3}{ }^{2-}$ and water in the space between the HT layers (Bezerra et. al, 2017). The most pronounced peak at the wavelength of $2923 \mathrm{~cm}^{-1}$ was observed in a sample calcined at $750{ }^{\circ} \mathrm{C}$ as it can be seen in Figure 3. Bending vibrations of $\mathrm{OH}$ groups were observed in the region of $1630 \mathrm{~cm}^{-1}$. Intensity of these peaks did not change during the calcination. The wavelength range of $1500 \mathrm{~cm}^{-1}$ to $1300 \mathrm{~cm}^{-1}$ was assigned to the interlayer anion $\mathrm{CO}_{3}{ }^{2-}$. In this area, a doublet in which one peak is more intense than the other is formed. The first peak belongs to an asymmetric stretching vibration of the $\mathrm{C}=\mathrm{O}$ double bond. The intensity of this peak is relatively low at all temperatures.

Tab. 3. Experimentally obtained wavelength $\left(100-1000 \mathrm{~cm}^{-1}\right)$ of sample Co/HT-1 $\left[\mathrm{cm}^{-1}\right]$.

\begin{tabular}{lccc}
\hline Samples & $\tau\left(\mathbf{A l O}_{4}\right)$ & $\tau(\mathbf{C o}-\mathbf{O})$ & $\tau\left(\mathbf{A l O}_{6}\right)$ \\
\hline Co/HT-1 & 737 & 599 & 554 \\
Co/HT-1/150 & 736 & 599 & 534 \\
Co/HT-1/250 & 669 & 573 & - \\
Co/HT-1/350 & 746 & 572 & 427 \\
Co/HT-1/450 & 764 & 567 & 437 \\
Co/HT-1/550 & 675 & 574 & - \\
Co/HT-1/650 & 677 & 574 & - \\
Co/HT-1/750 & 673 & 577 & - \\
\hline
\end{tabular}

Due to the decrease not only in water but also in $\mathrm{CO}_{3}{ }^{2-}$ groups during the calcination at higher temperatures, peaks above $550{ }^{\circ} \mathrm{C}$ are no longer recorded. The more intense peak of this doublet is a peak in the $1500 \mathrm{~cm}^{-1}$ region, which represents the interaction of the $\mathrm{CO}_{3}{ }^{2-}$ anion with $\mathrm{OH}$ groups found in the octahedral structure of the cationic layer of HT. With the increasing calcination temperature, the intensity decreases as it can be seen in Figure 3 where the intensity is minimal at $750{ }^{\circ} \mathrm{C}$. At calcination temperatures of $350{ }^{\circ} \mathrm{C}, 650^{\circ} \mathrm{C}$ and $750{ }^{\circ} \mathrm{C}$, a peak of low intensity $\left(\sim 1030 \mathrm{~cm}^{-1}\right)$ was observed.

Tab. 2. Experimentally obtained wavelength $\left(3500-1000 \mathrm{~cm}^{-1}\right)$ of sample Co/HT-1 $\left[\mathrm{cm}^{-1}\right]$.

\begin{tabular}{|c|c|c|c|c|c|c|}
\hline Samples & $\tau\left(\mathbf{H}_{2} \mathbf{O}\right)$ & $\begin{array}{l}\mathrm{CO}_{3}{ }^{2-}-\mathrm{H}_{2} \mathrm{O} \\
(\text { interaction) }\end{array}$ & $v\left(\mathbf{H}_{2} \mathbf{O}\right)$ & $\tau(\mathbf{C}=\mathbf{O})$ & $\begin{array}{l}(\mathrm{C}-\mathrm{O})-\mathrm{OH} \\
(\text { interaction })\end{array}$ & $v(\mathbf{A l}-\mathbf{O H})$ \\
\hline Co/HT-1 & 3490 & - & 1653 & 1510 & 1366 & - \\
\hline Co/HT-1/150 & 3490 & - & 1654 & 1510 & 1364 & - \\
\hline Co/HT-1/250 & 3480 & 2364 & 1632 & 1474 & 1368 & - \\
\hline Co/HT-1/350 & 3473 & 2924 & 1632 & 1506 & 1371 & 1026 \\
\hline Co/HT-1/450 & 3480 & - & 1631 & 1465 & 1368 & - \\
\hline Co/HT-1/550 & 3470 & - & 1635 & - & 1382 & - \\
\hline Co/HT-1/650 & 3480 & 2924 & 1638 & - & 1378 & 1030 \\
\hline Co/HT-1/750 & 3473 & 2923 & 1630 & - & - & 1035 \\
\hline
\end{tabular}




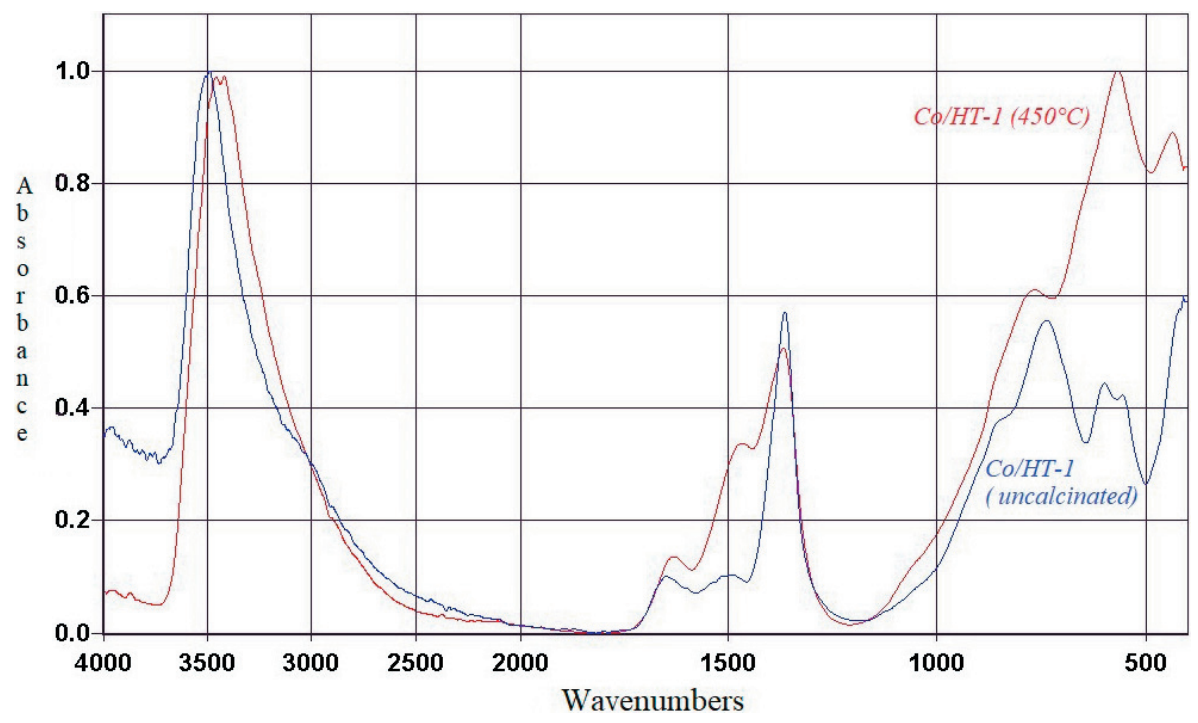

Fig. 2. Comparison of experimentally obtained IR spectrum of uncalcined Co/HT-1 and $\mathrm{Co} / \mathrm{HT}-1$ calcined at $450{ }^{\circ} \mathrm{C}$.

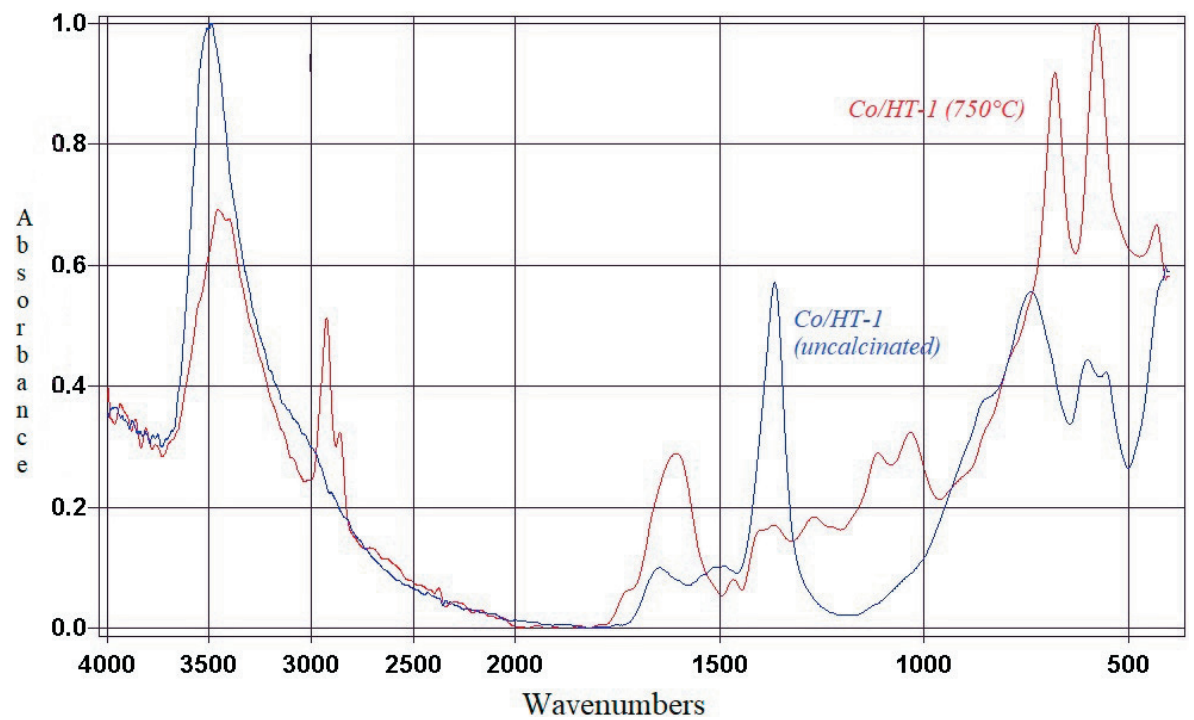

Fig. 3. Comparison of experimentally obtained IR spectrum of uncalcined Co/HT-1 and Co/HT- 1 calcined at $750{ }^{\circ} \mathrm{C}$.

Perez-Ramirez et al. (2001) reported that this low peak belongs to the bending vibration of $\mathrm{Al}-\mathrm{OH}$. Débora M. Bezerra et al. indicated that this vibration is caused by the bending vibrations of the structure of Al-OH-Al (Bezerra et. al, 2017). Vibrations in the wavelength range of $670-740 \mathrm{~cm}^{-1}$, with relatively high intensity, are caused by stretching vibrations of isolated $\mathrm{AlO}_{4}$ tetrahedra.

Intensity of these vibrations increases with the increasing calcination temperature, the most pronounced increase can be observed with $\mathrm{Co} /$ HT-1/750 (Fig. 3) and Co/HT-1/450 (Fig. 2). At temperatures from $450{ }^{\circ} \mathrm{C}$ to $750{ }^{\circ} \mathrm{C}$, tetrahedral $\mathrm{AlO}_{4}$ bands create a doublet with more intense stretching vibrations of $\mathrm{Co}-\mathrm{O}$ bonding. Their intensity increases with the increasing calcination temperature due to the spinel structure formation. As the last vibrations in the IR spectrum, stretching vibrations of the $\mathrm{Al}-\mathrm{O}$ bond in the octahedral structure of $\mathrm{AlO}_{6}$ can be observed. These vibrations, completely disappear at calcination higher temperatures (Kloproggel at al., 1999; Jitianu et al., 2000).

\section{Co/HT-4}

The second sample was Co/HT-4, which has a higher cobalt content. The stretching vibration of $\mathrm{OH}$ from water in the interlayer space was found at the wavelength of $3500 \mathrm{~cm}^{-1}$. The peak intensity decreased with the increasing calcination temperature. The most significant decrease was observed with $\mathrm{Co} / \mathrm{HT}-4 / 750$ (Fig. 4). A relatively intense 
peak in this sample represents the interaction of the hydroxyl group from water with the $\mathrm{CO}_{3}{ }^{2-}$ anion in the interlayer space.

Bending vibrations of $\mathrm{OH}$ groups from interlayer $\mathrm{H}_{2} \mathrm{O}$ in the area from $1600 \mathrm{~cm}^{-1}$ to $1700 \mathrm{~cm}^{-1}$ are low in the uncalcined sample and they decreased with the calcination temperature. Stretching vibrations of interlayer anion $\mathrm{CO}_{3}{ }^{2-}$ are divided into two types, as it can be seen in Table 4 . The first vibration at the wavelength of $1500 \mathrm{~cm}^{-1}$ belongs to the asymmetric stretching vibration of the $\mathrm{C}=\mathrm{O}$ double bond. The intensity in uncalcined sample is quite high; the amount of interlayer anions decreased and consequently these vibrations completely disappeared with increasing calcination (Fig. 4).

A similar intensity decrease was observed at the wavelength of $1300-1400 \mathrm{~cm}^{-1}$, which corresponds to the interaction between the $\mathrm{CO}_{3}{ }^{2-}$ anion and the $\mathrm{OH}$ group belonging to the octahedral structure of hydrotalcite. These vibrations caused by the interlayer anion have not been observed above $450{ }^{\circ} \mathrm{C}$ (Bezerra et al., 2017; Pérez-Ramírez et al., 2001; Kloproggel at al., 1999). Vibrations at wavelengths from 400 to $800 \mathrm{~cm}^{-1}$ were ascribed to the stretching vibration of metals with oxygen. The separate tetrahedral structure of $\mathrm{AlO}_{4}$ creates peaks in the region of $600-700 \mathrm{~cm}^{-1}$ with relatively low intensity in the uncalcined sample.

With the increasing calcination temperature, the intensity increased and at the calcination temperature of $550^{\circ} \mathrm{C}$, a doublet with high intensity peak ascribed to the stretching vibration of the $\mathrm{Co}-\mathrm{O}$ bond was formed. A well-visible change is shown in Figure 4 , where an increase in the intensity of the $\mathrm{Co}-\mathrm{O}$ bond vibration area occurs. In the uncalcined Co/ HT-4 sample, stretching vibrations of the octahedron $\mathrm{AlO}_{6}$ were also observed but they completely disappeared at $250{ }^{\circ} \mathrm{C}$ (Pérez-Ramírez et al., 2001; Kloproggel at al., 1999; Wiley \& Sons).

\section{Comparison of Co/HT-1 and Co/HT-4}

Using the FTIR analysis, two samples containing different amounts of cobalt in their structure were also compared. The first was a Co/HT-1 sample,

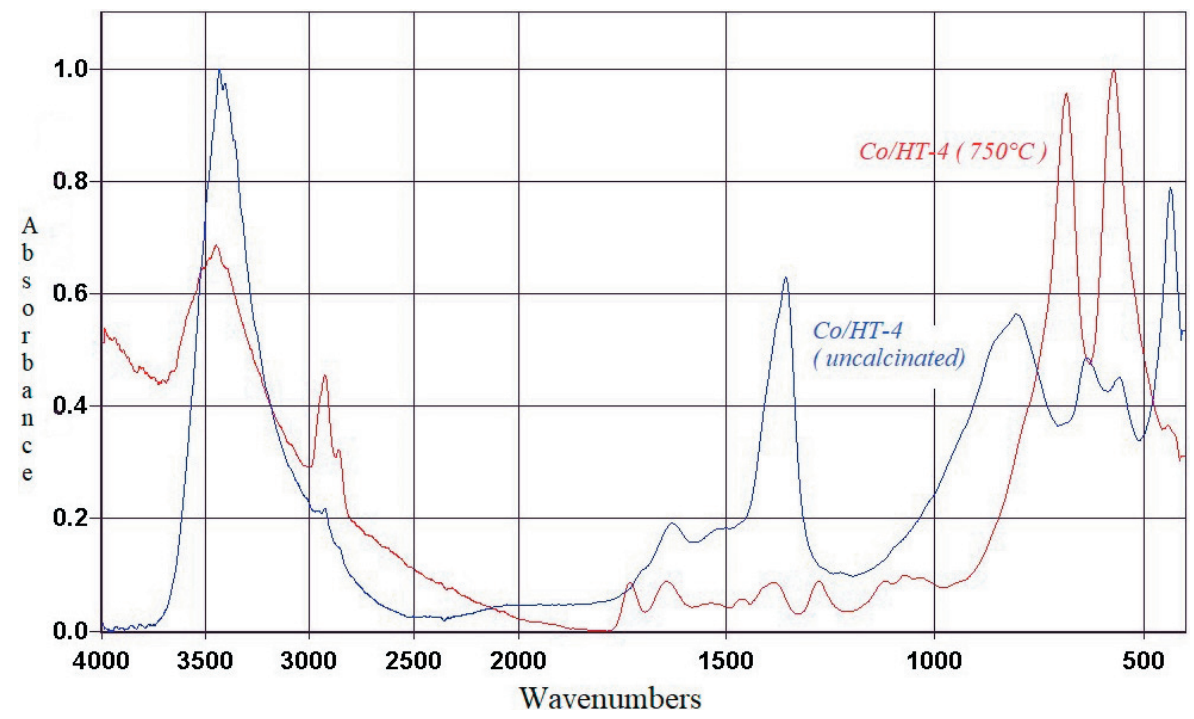

Fig. 4. Comparison of experimentally obtained IR spectrum of uncalcined Co/HT-4 and $\mathrm{Co} / \mathrm{HT}-4$ calcined at $750{ }^{\circ} \mathrm{C}$.

Tab. 4. Experimentally obtained wavelength $\left(3500-1000 \mathrm{~cm}^{-1}\right)$ of sample Co/HT-4 $\left[\mathrm{cm}^{-1}\right]$.

\begin{tabular}{lcccccc}
\hline Samples & $\tau\left(\mathbf{H}_{\mathbf{2}} \mathbf{O}\right)$ & $\begin{array}{c}\mathbf{C O}_{3}{ }^{2-}-\mathbf{H}_{2} \mathbf{O} \\
(\text { interaction })\end{array}$ & $\nu\left(\mathbf{H}_{2} \mathbf{O}\right)$ & $\tau(\mathbf{C}=\mathbf{O})$ & $\begin{array}{c}(\mathbf{C}-\mathbf{O})-\mathbf{O H} \\
\text { (interaction) }\end{array}$ & $\nu(\mathbf{A l}-\mathbf{O H})$ \\
\hline Co/HT-4 & 3475 & - & 1630 & - & 1357 & - \\
Co/HT-4/150 & 3480 & - & 1625 & 1518 & 1374 & - \\
Co/HT-4/250 & 3482 & - & 1712 & 1518 & 1369 & 1227 \\
Co/HT-4/350 & 3483 & - & 1713 & 1507 & 1366 & 1093 \\
Co/HT-4/450 & 3482 & - & 1703 & 1507 & 1408 & 1227 \\
Co/HT-4/550 & 3495 & - & 1701 & - & 1365 & 1092 \\
Co/HT-4/650 & 3492 & - & 1635 & - & 1412 & 1028 \\
Co/HT-4/750 & 3493 & 2926 & 1730 & - & 1383 & - \\
\hline
\end{tabular}


Tab. 5. Experimentally obtained wavelength $\left(1000-400 \mathrm{~cm}^{-1}\right)$ of sample Co/HT-4 $\left[\mathrm{cm}^{-1}\right]$.

\begin{tabular}{lccc}
\hline Samples & $\tau\left(\mathbf{A l O}_{\mathbf{4}}\right)$ & $\tau(\mathbf{C o}-\mathbf{O})$ & $\tau\left(\mathrm{AlO}_{6}\right)$ \\
\hline Co/HT-4 & 635 & 558 & 434 \\
Co/HT-4/150 & 787 & 616 & 440 \\
Co/HT-4/250 & 785 & 611 & 446 \\
Co/HT-4/350 & 800 & 534 & - \\
Co/HT-4/450 & 784 & 613 & 551 \\
Co/HT-4/550 & 679 & 570 & - \\
Co/HT-4/650 & 684 & 574 & - \\
Co/HT-4/750 & 684 & 570 & - \\
\hline
\end{tabular}

which contained less cobalt (13.95 g) in its structure, in contrast to the second sample, with more cobalt $(44.4 \mathrm{~g})$ in its hydrocalcite sheets. In Figure 5, where uncalcined samples are depicted, it can be seen that the sample with higher cobalt content (Co/ HT-4) shows higher intensities but the difference is minimal. Significant vibration at the wavelength of $440 \mathrm{~cm}^{-1}$ was ascribed to the stretching vibration of the $\mathrm{AlO}_{6}$ octahedron, which is attributed to the fivefold amount of aluminium in the Co/HT-4 sample $(50 \mathrm{~g})$ in comparison with Co/HT-1 $(10 \mathrm{~g})$. It can be seen that the differences in the wavelength in this two samples are only minimal.

\section{$\mathrm{ZnNi} / \mathrm{HT}-6$}

$\mathrm{ZnNi}$ /HT-6 sample contains $\mathrm{Zn}, \mathrm{Ni}, \mathrm{Mg}$ and $\mathrm{Al}$ in its structure. As it can be seen in Table 5, the first peaks at the intensity of $3400 \mathrm{~cm}^{-1}$ are stretching vibrations of water located in the interlayer space. Peak intensity decreases with the increasing calcination temperature. The lowest intensity was observed at $550{ }^{\circ} \mathrm{C}$ (Figure 6) and $750{ }^{\circ} \mathrm{C}$ (Figure 7). This is caused by the loss of water in the interlayer space due to calcination. In the wavelength range of $2900 \mathrm{~cm}^{1}$, interaction between $\mathrm{CO}_{3}{ }^{2-}$ and hydroxyl molecules from the interlayer space was observed; showing

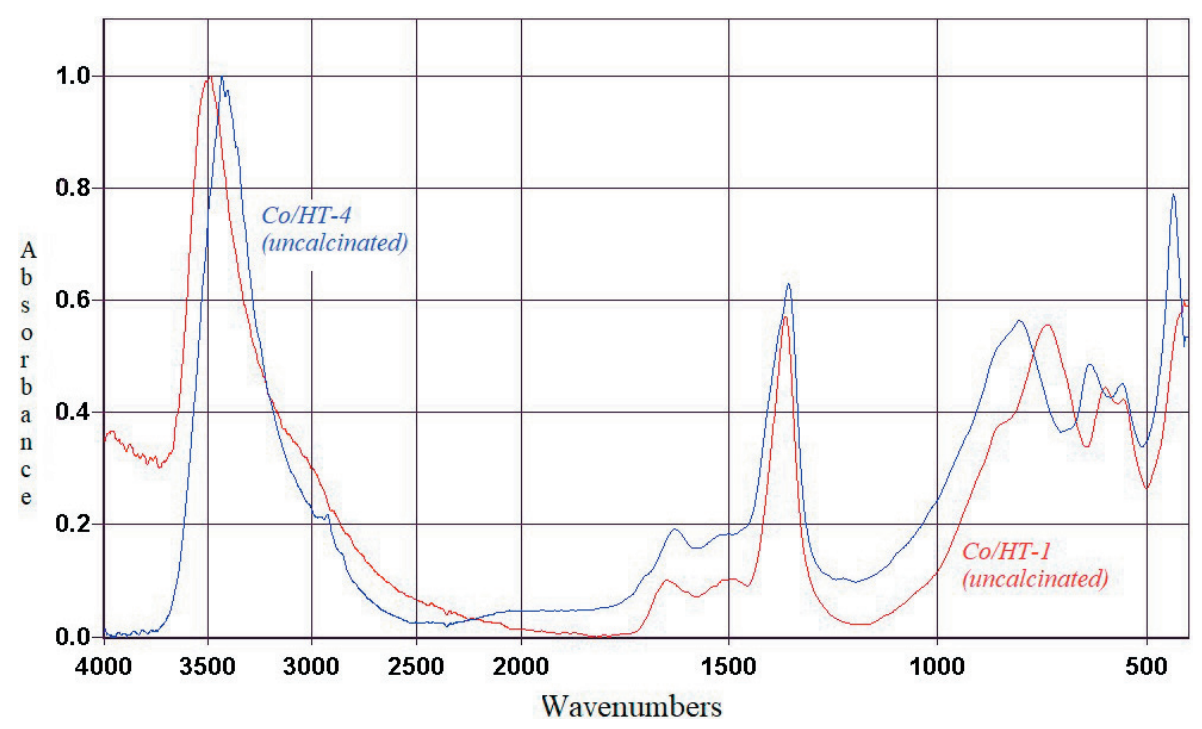

Fig. 5. Comparison of experimentally obtained IR spectrum of uncalcined Co/HT-1 and uncalcined Co/HT-4.

Tab. 6. Experimentally obtained wavelength $\left(3500-1100 \mathrm{~cm}^{-1}\right)$ of sample ZnNi/HT-6 $\left[\mathrm{cm}^{-1}\right]$.

\begin{tabular}{|c|c|c|c|c|c|c|}
\hline Samples & $\tau\left(\mathbf{H}_{2} \mathbf{O}\right)$ & $\begin{array}{l}\mathrm{CO}_{3}{ }^{2-}-\mathrm{H}_{2} \mathrm{O} \\
\text { (interaction) }\end{array}$ & $v\left(\mathbf{H}_{2} \mathbf{O}\right)$ & $\tau(\mathbf{C}=\mathbf{O})$ & $\begin{array}{c}(\mathrm{C}-\mathrm{O})-\mathrm{OH} \\
\text { (interaction) }\end{array}$ & $\begin{array}{c}(\mathrm{C}-\mathrm{O}) \\
\text { Bidentat } \\
\text { konfig. }\end{array}$ \\
\hline $\mathrm{ZnNi} / \mathrm{HT}-6$ & 3432 & - & 1634 & 1487 & 1368 & - \\
\hline $\mathrm{ZnNi} / \mathrm{HT}-6 / 150$ & 3466 & 2951 & 1624 & 1475 & 1379 & - \\
\hline $\mathrm{ZnNi} / \mathrm{HT}-6 / 250$ & 3435 & 2923 & 1624 & 1527 & 1386 & - \\
\hline $\mathrm{ZnNi} / \mathrm{HT}-6 / 350$ & 3454 & 2924 & 1629 & 1509 & 1412 & - \\
\hline $\mathrm{ZnNi/HT-6/450}$ & 3432 & 2924 & 1632 & 1503 & 1416 & 1280 \\
\hline $\mathrm{ZnNi/HT-6/550}$ & 3434 & 2360 & 1632 & 1496 & 1418 & 1282 \\
\hline $\mathrm{ZnNi} / \mathrm{HT}-6 / 650$ & 3441 & 2926 & 1633 & 1511 & 1417 & 1286 \\
\hline $\mathrm{ZnNi} / \mathrm{HT}-6 / 750$ & 3418 & 2935 & 1633 & 1473 & 1406 & - \\
\hline
\end{tabular}


Tab. 7. Experimentally obtained wavelength $\left(1000-400 \mathrm{~cm}^{-1}\right)$ of sample ZnNi/HT-6 [cm-1].

\begin{tabular}{|c|c|c|c|c|}
\hline Samples & $\tau\left(\mathrm{AlO}_{4}\right)$ & $\tau\left(\mathrm{AlO}_{6}-\mathrm{NiO}_{6}\right)$ & $\begin{array}{c}\mathrm{NiAl}_{2} \mathrm{O}_{4} \\
\text { (spinel structure) }\end{array}$ & $\tau(\mathbf{Z n}-\mathbf{O H})$ \\
\hline $\mathrm{ZnNi/HT-6}$ & 1031 & 788 & 636 & 441 \\
\hline $\mathrm{ZnNi} / \mathrm{HT}-6 / 150$ & 1022 & 764 & 629 & 446 \\
\hline $\mathrm{ZnNi} / \mathrm{HT}-6 / 250$ & 1038 & 786 & 611 & 443 \\
\hline $\mathrm{ZnNi} / \mathrm{HT}-6 / 350$ & 1041 & 790 & 610 & 482 \\
\hline $\mathrm{ZnNi} / \mathrm{HT}-6 / 450$ & - & 808 & 608 & 490 \\
\hline $\mathrm{ZnNi} / \mathrm{HT}-6 / 550$ & - & 792 & 589 & 488 \\
\hline $\mathrm{ZnNi} / \mathrm{HT}-6 / 650$ & - & 799 & - & 486 \\
\hline $\mathrm{ZnNi} / \mathrm{HT}-6 / 750$ & 1040 & 771 & - & 479 \\
\hline
\end{tabular}

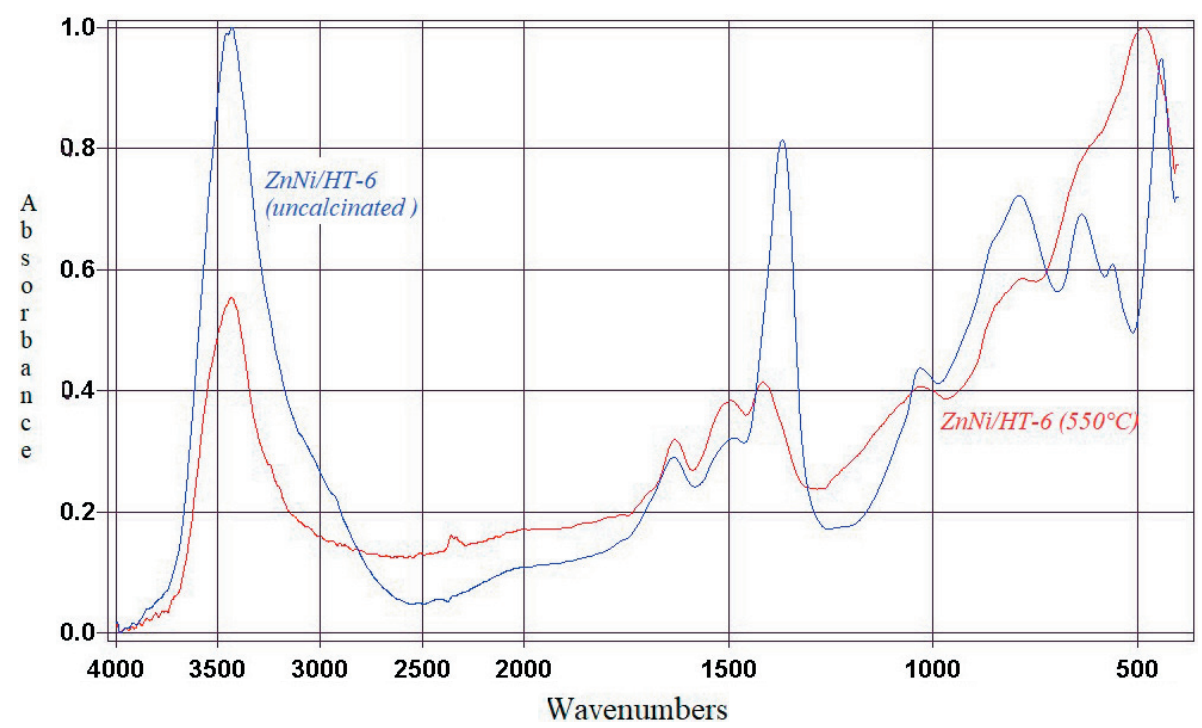

Fig. 6. Comparison of experimentally obtained IR spectrum of uncalcined $\mathrm{ZnNi} / \mathrm{HT}-6$ and $\mathrm{ZnNi}$ /HT-6 calcined at $550{ }^{\circ} \mathrm{C}$.

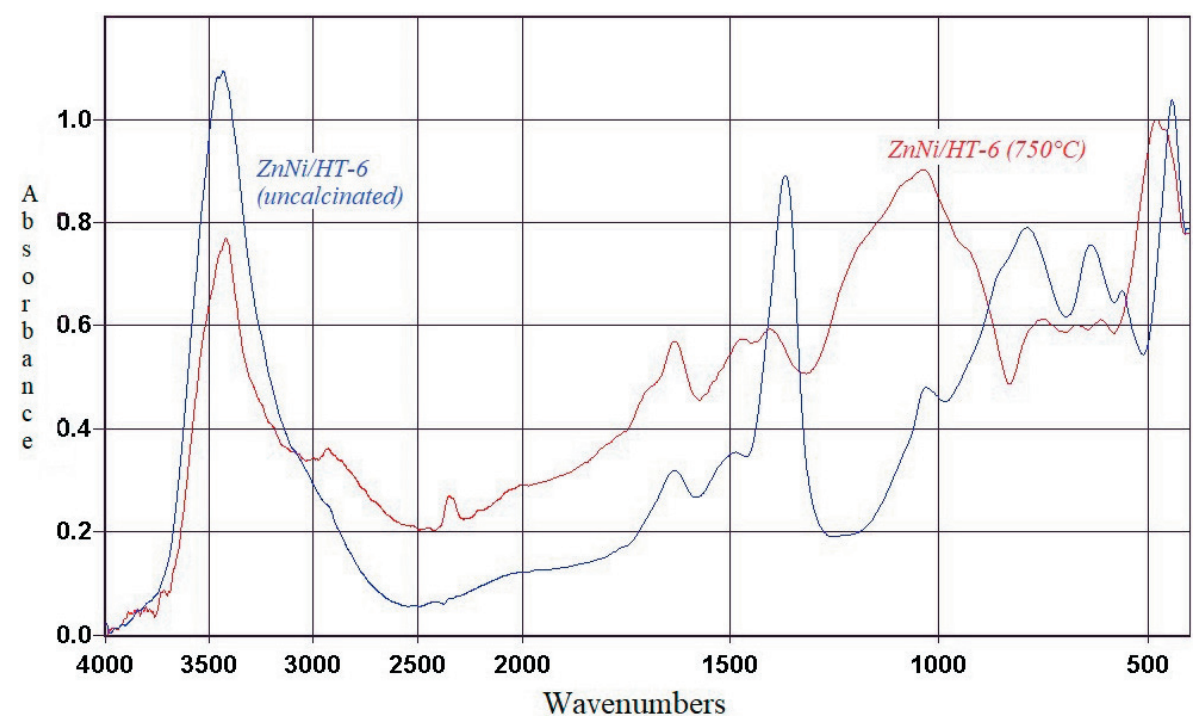

Fig. 7. Comparison of experimentally obtained IR spectrum of uncalcined ZnNi/HT-6 and $\mathrm{ZnNi} / \mathrm{HT}-6$ calcined at $750^{\circ} \mathrm{C}$. 
a relatively low intensity peak in the IR spectrum which did not change during the calcination. Another stable peak shown in the IR record is the bending vibration of water $\left(\sim 1630 \mathrm{~cm}^{-1}\right)$; its intensity remained unchanged despite the changing calcination temperature. In the area of $1500 \mathrm{~cm}^{-1}$, a doublet representing the $\mathrm{CO}_{3}{ }^{2-}$ vibration, which is an interlayer anion, appeared. The first low intensity peak from the doublet represents the stretching vibration of the $\mathrm{C}=\mathrm{O}$ double bond. The intensity of this peak compared to the second one in the doublet is low. In the wavelength range of $1400-1500 \mathrm{~cm}^{-1}$, the second peak from the doublet represents the interaction between the $\mathrm{C}-\mathrm{O}$ bond and the $\mathrm{OH}$ molecule that belongs to the octahedral structure of the hydrotalcite layer. The peak intensity in uncalcined sample
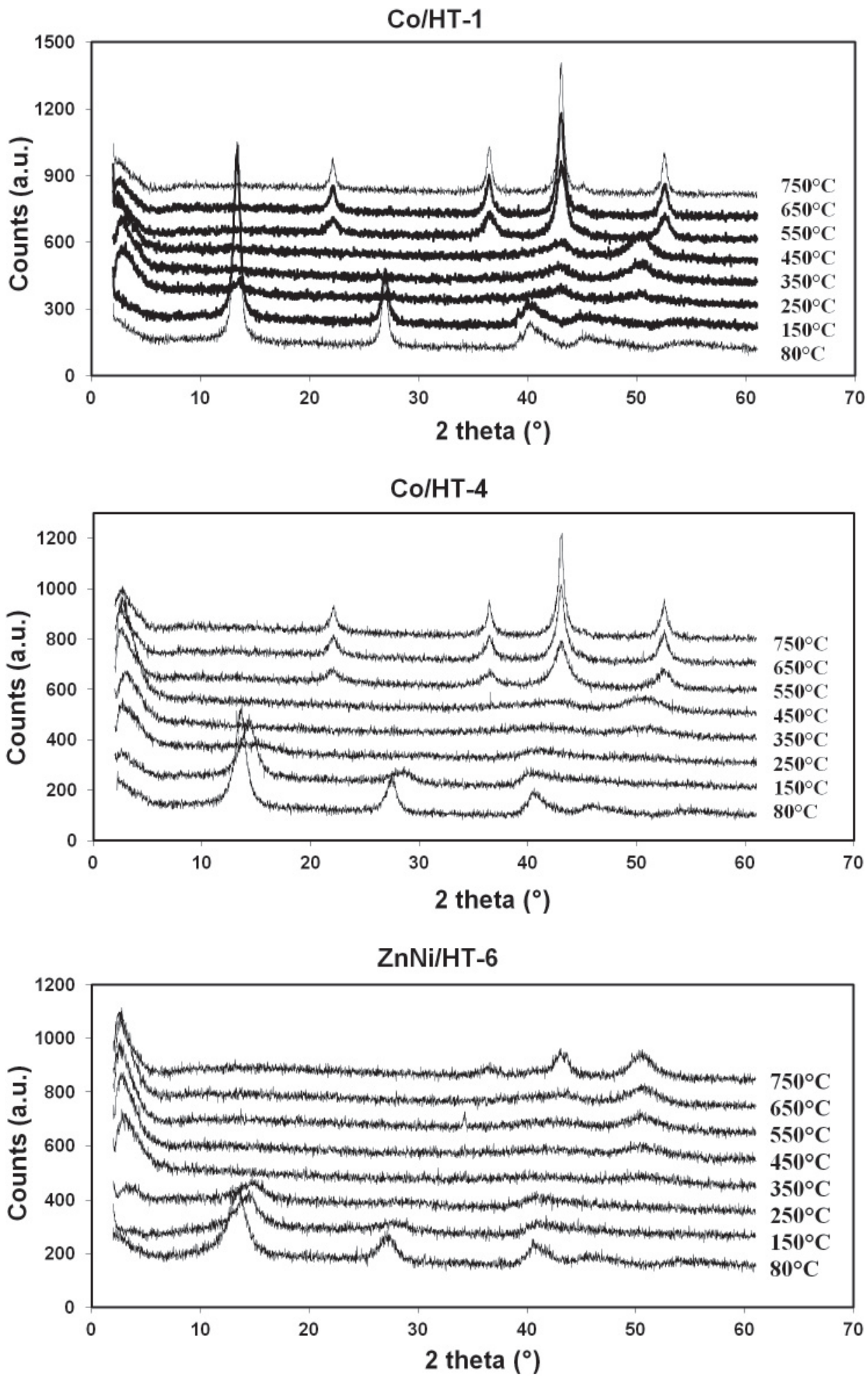

Fig. 8. XRD pattern of prepared hydrotalcites (Co/HT-1, Co/HT-4 and ZnNi/HT-6). 
is relatively high but its intensity decreases with the increasing calcination temperature.

For $\mathrm{ZnNi} / \mathrm{HT}-6 / 350, \mathrm{ZnNi} / \mathrm{HT}-6 / 450, \mathrm{ZnNi} / \mathrm{HT}$ 6/550, and $\mathrm{ZnNi} / \mathrm{HT}-6$, low intensity vibrations around $1200 \mathrm{~cm}^{-1}$ were observed. According to the study by Pérez-Ramiréz et al. (2001) this vibration represents two $\mathrm{C}-\mathrm{O}$ bonds, the so-called bidentate configuration (Bezerra et al., 2017; Kloproggel at al., 1999; Pérez-Ramírez et al., 2001). Vibrations visible at the wavelength of $1030 \mathrm{~cm}^{-1}$ were ascribed to the bending vibration of Al-OH from the hydrotalcite layered structure. The most pronounced increase in this vibration intensity was observed at $750{ }^{\circ} \mathrm{C}$ (Fig. 7) at the wavelength of $1040 \mathrm{~cm}^{-1}$. In the vibration area of $800 \mathrm{~cm}^{-1}$, a relatively low intensity peak can be seen, which according to several authors (Bezerra et al., 2017; Kloproggel at al., 1999; Pérez-Ramírez et al., 2001) corresponds to the stretching vibration of the octahedral structures of $\mathrm{AlO}_{6}$ and $\mathrm{NiO}_{6}$. The intensity of these vibrations remained substantially unchanged at different calcination temperatures with only minor a decrease at higher temperatures. At the wavelength of about $600 \mathrm{~cm}^{-1}$, a visible peak representing the spinel structure of $\mathrm{NiAl}_{2} \mathrm{O}_{4}$ can be seen. Vibration intensity was low and it completely disappeared at $650{ }^{\circ} \mathrm{C}$ and $750{ }^{\circ} \mathrm{C}$ (Pérez-Ramírez et al., 2001). Wavelengths in the $400 \mathrm{~cm}^{-1}$ area were attributed to the stretching vibrations of the $\mathrm{Zn}-\mathrm{OH}$ bond. The intensity directly increased with the increasing calcination temperature.

\section{XRD pattern}

Results of the FTIR-spectra are supported by the results of XRD-spectra of the prepared hydrotalctite samples calcined at temperatures up to $750{ }^{\circ} \mathrm{C}$, Fig. 8 .

Basic XRD-spectra of all as-synthesized hydrotalcites, dried at $80^{\circ} \mathrm{C}$, are practically the same, which indicates reflexes of hydrotalcite $\mathrm{Mg}_{2} \mathrm{Al}_{2} \mathrm{CO}_{3}(\mathrm{OH})_{6} \cdot 4 \mathrm{H}_{2} \mathrm{O}$, where basic metals are isomorphously replaced by $\mathrm{Co}$, or $\mathrm{Zn}$ and/or Ni. Co-MgAl, and $\mathrm{NiZn-MgAl}$ hydrotalcites have the same spectra thus it is impossible to separate them.

Thermal treatment of both Co-hydrotalcites up to $450{ }^{\circ} \mathrm{C}$ resulted in the loss of their hydrotalcite structure at about $150-250{ }^{\circ} \mathrm{C}$, and the creation of a partially amorphous mixture of metal oxides. Reflexes of Co/HT-1 and Co-HT-4 samples calcined at $450{ }^{\circ} \mathrm{C}$ at about 43 and $50{ }^{\circ} 2$ theta correspond to mixed metal oxides (e.g. MgAl oxides, $\mathrm{CoMg}$ oxides); spectra of $\mathrm{MgO}, \mathrm{Al}_{2} \mathrm{O}_{3}$ and $\mathrm{CoO}$ oxides are overlapped in this range and cannot be separated. An increase in the calcination temperature from $550^{\circ} \mathrm{C}$, a spinel structure with sharpness apparently increasing with the temperature up to $750{ }^{\circ} \mathrm{C}$ are created in the XRD spectra. XRD-spectra of both Co-hydrotalcites correspond to the overlaid spinel structure of MgAl-oxide and CoAl-oxide.

The basic XRD-spectra of ZnNi/HT6 hydrotalcite dried at $80{ }^{\circ} \mathrm{C}$ are very similar to those of both Co-hydrotalcites, decreasing in the intensity under thermal treatment to $150-250{ }^{\circ} \mathrm{C}$. After the calcination at $350{ }^{\circ} \mathrm{C}$, the XRD-spectra showed almost amorphous structure indicating the oxide phase at about $50^{\circ} 2$ theta. The more expressed spectrum of mixed oxides can be observed by the increase of calcination temperature up to $750{ }^{\circ} \mathrm{C}$ even without traces of the spinel structure at the maximum calcination temperature. XRD-spectra of the $\mathrm{ZnNi}$ / HT-6 sample treated at $750{ }^{\circ} \mathrm{C}$ correspond with those of the mixed oxides: $\mathrm{ZnAl}$ oxide, NiZn-oxide, $\mathrm{NiAl}$ oxide, $\mathrm{MgAl}$ oxide as well as pure $\mathrm{MgO}$.

\section{Conclusion}

The work was focused on the FTIR study of magnesium-aluminium hydrotalcite analysing its structure changes due to calcination. Three samples were prepared by simultaneous precipitation. The first sample contained cobalt, the second sample contained 1,5- fold amount of cobalt compared with the first hydrotalcite sample while the last sample contained zinc and nickel. All samples were calcined at temperatures from 150 to $750{ }^{\circ} \mathrm{C}$ and subsequently studied in form of $\mathrm{KBr}$ tablets in a GENESIS single-ray spectrometer. During the evaluation, peak intensity in individual areas and wavelength variation of individual vibrations have been investigated. Based on the comparison of the uncalcined spectra and spectra at all calcination temperatures, it was found that the stretching vibration of water from the interlayer space, around the area of $\sim 3500 \mathrm{~cm}^{-1}$, varied. Increasing the calcination temperature led to a decrease in the intensity of these stretching vibrations. It has also been observed that due to calcination, the peak intensity $\left(\sim 1500-1700 \mathrm{~cm}^{-1}\right)$ representing the stretching vibrations of interlayer anions $\mathrm{CO}_{3}{ }^{2-}$ decreased. The most distinct change was observed in the $\mathrm{ZnNi}$ / HT-6 sample, where a significant decrease in the intensity of $\sim 1400 \mathrm{~cm}^{-1}$ was seen, especially when comparing the uncalcined sample and that calcined at $750{ }^{\circ} \mathrm{C}$. The most distinct changes were observed at wavelengths from 400 to $700 \mathrm{~cm}^{-1}$. The peaks found in this area were ascribed to the stretching vibrations of the metals with oxygen. In the first Co/HT-1 sample, a rapid increase in the intensity from 500 to $700 \mathrm{~cm}^{-1}$ was well observed at $750{ }^{\circ} \mathrm{C}$.

There is a very intense doublet formed by the stretching vibrations of tetrahedral $\mathrm{AlO}_{4}$ with more intense stretching vibrations of $\mathrm{Co}-\mathrm{O}$ bonding. The spinel 
structure, which affects the resulting properties of hydrotalcite as a catalyst, was formed. In the second Co/HT-4 sample, a significant increase in the wavelength range of $500-700 \mathrm{~cm}^{-1}$ was observed. The last sample, $\mathrm{ZnNi}$ /HT-6, which contains zinc and nickel in its structure, also showed high intensity in the area of stretching vibrations of metal with oxygen $\left(\sim 500-700 \mathrm{~cm}^{-1}\right)$. For this sample, a significant strip representing the $\mathrm{NiAl}_{2} \mathrm{O}_{4}$ spinel structure was found in this area.

The presented results of FTIR-spectra were confirmed by the XRD pattern of prepared hydrotalcites calcined at temperatures from $150{ }^{\circ} \mathrm{C}$ to $750{ }^{\circ} \mathrm{C}$.

\section{Acknowledgement}

This research has been financially supported by the Slovak Research and Development Agency under No. APVV-150449 and $A P V V-16-0097$.

\section{References}

Bezerra DM et al. (2017) Materials Characterization. vol. 1: 29-36.

Cavani F, Trifirb F, Vaccari A (1991) Catalysis Today. vol. 11: 173-301.

Muriithi GN et al. (2016) Powder Technology. vol. 1: 299-309.
Yang C, Liao L et al. (2016) Journal of Colloid and Interface Science. vol. 1: 115-120.

Kloproggel JT, Frost RL (1999) Journal of Solid State Chemistry. vol. 146: 506-515.

Pérez-Ramírez J et al. (2001) Vibrational Spectroscopy. vol. 27: 75-88.

Wei JHM, Li B, Kang Y, Evans DG, Duan X (2005) Layered Double Hydroxides vol. 1: 89-119.

Wiley \& Sons J. Kirk-Othmer (2000) Encyclopedia of Chemical Technology John Wiley \& Sons.

Jitianu M et al. (2000) Vibrational Spectroscopy. vol. 22: 75-86.

Kikhtyanin O, Tišler Z, Velvarská R, Kubička D (2016) Applied Catalysis A: General. vol. 536: 85-96.

Salomão R et al. (2013) Interceram - refractories manual I/2013: 187-191

Basag S et al. (2016) Applied Clay Science. vol. 129: 122-130.

Baskaran T et al. (2015) Royal society of chemistry vol. 5: 98853-98875.

Muriithi GN et al. (2016) Powder Technology vol. 312: 299-309.

Shekoohi K et al. (2017) MethodsX, vol. 4: 86-94.

Rao MM et al. (2004) Materials Research Bulletin, vol. 40: 347-359.

Rahman A (2013) International Journal of Engineering, vol. 4: 75-82.

Xie X et al. (2008) Catalysis Communications, vol. 9: 1128-1132.

Mehrotra R (2006) Encyclopedia of Analytical Chemistry. Jitianu M et al. (2000) Vibrational Spectroscopy, vol. 22. 